This item was submitted to Loughborough's Research Repository by the author.

Items in Figshare are protected by copyright, with all rights reserved, unless otherwise indicated.

\title{
Making the case for developing new 'PE-for-Health' pedagogies
}

PLEASE CITE THE PUBLISHED VERSION

http://dx.doi.org/10.1080/00336297.2013.773531

\section{PUBLISHER}

(C) Taylor \& Francis (Routledge)

VERSION

AM (Accepted Manuscript)

LICENCE

CC BY-NC-ND 4.0

\section{REPOSITORY RECORD}

Armour, Kathleen, and Josephine P. Harris. 2019. "Making the Case for Developing New 'pe-for-health' Pedagogies". figshare. https://hdl.handle.net/2134/11107. 
This item was submitted to Loughborough's Institutional Repository (https://dspace.lboro.ac.uk/) by the author and is made available under the following Creative Commons Licence conditions.

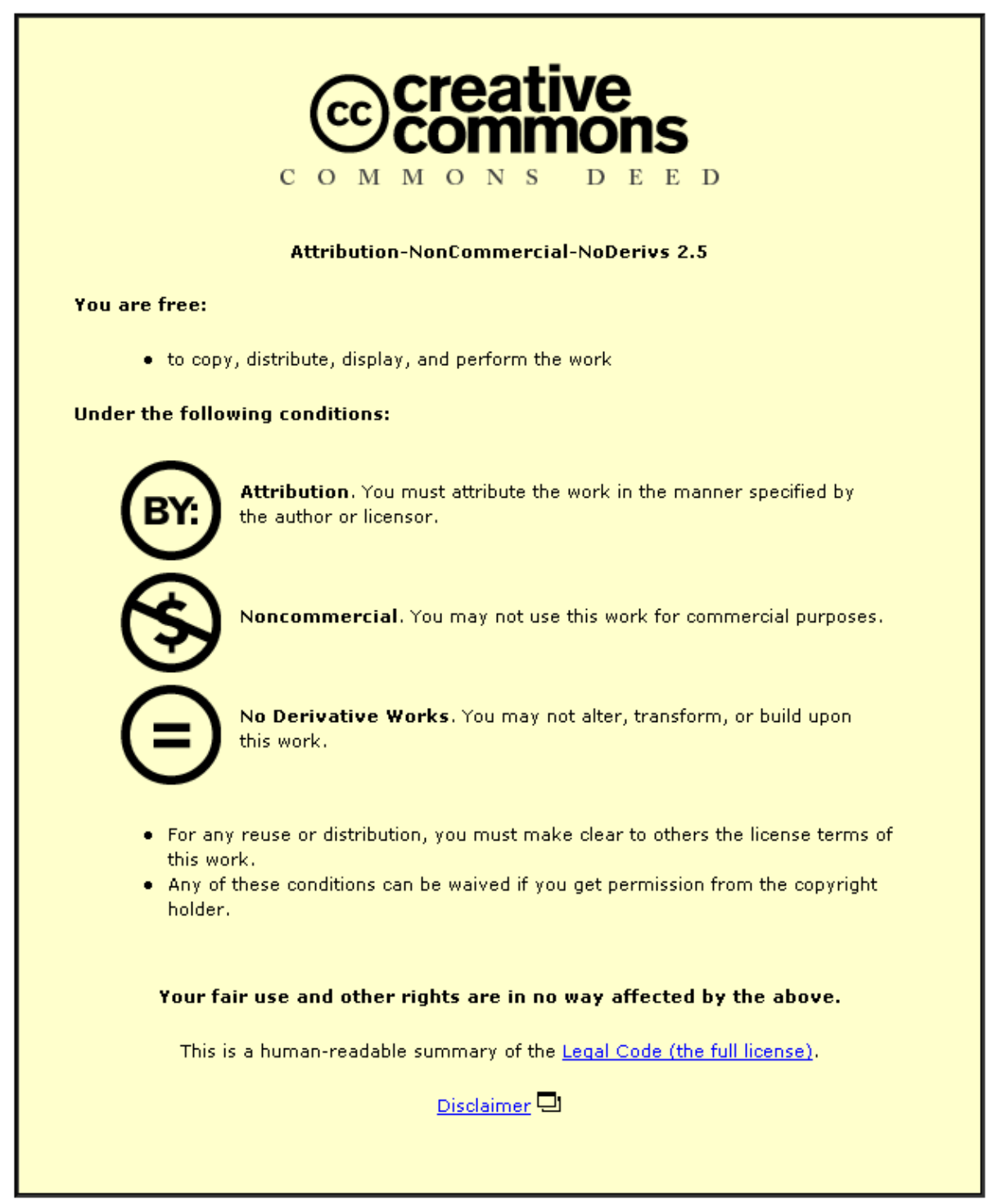

For the full text of this licence, please go to: http://creativecommons.org/licenses/by-nc-nd/2.5/ 


\title{
RUNNING HEAD: PE-FOR-HEALTH PEDAGOGIES
}

\section{Making the Case for Developing New 'PE-for-Health' Pedagogies}

\begin{abstract}
This paper argues for a new direction in research on health education within physical education (PE). Governments are increasingly looking to schools as a convenient form of public health investment. PE is implicated in health because of its core focus on physical activity, but there is little evidence to suggest that PE improves health outcomes. Moreover, although there has been interest in health-focussed curriculum activities and interventions, there has been a surprising silence around the pedagogies to be used in the health dimension of PE practices. This paper critically reviews claims made about the role of PE in public health, and considers how health has been conceptualised in PE over time. The professional development needs of PE teachers in health are examined, and it is argued that the development of new, complex, evidence-based and personalised 'PE-forhealth' pedagogies is the next major step to be taken in PE research.
\end{abstract}

Keywords: physical education pedagogy, PE-health pedagogies, public health

Obesity, cardiovascular disease, and psychological ill-health are identified as major public health problems worldwide, and all have been associated with increases in sedentary living (Australian Institute of Health and Welfare, 2010; US Department of Health and Human Services (USDHHS), 2008; World Health Organisation (WHO), 2010). In particular, the strong trend towards a steady rise in body weight in the 'developed' world over recent decades has resulted in reports of an obesity 'epidemic' which has led to much passion in the media. A respected journalist reporting in The Times newspaper, after attending a National Obesity Forum in London, dismissed the complexity of many of the arguments presented there about the causes of obesity with the following comments:

'we all know the truth...A fatter society tends to be one where people eat more high-density foodstuffs and take less exercise... Nor is the answer "more school sports". One part of the solution is certainly more exercise, and that could just as well be tap-dance as rounders. In fact, tap-dance would be better'.

(Aronovitch, The Times, $16^{\text {th }}$ October, 2007, p.17.). 
A week or so later, a member of the government made the suggestion that: 'We should stigmatise those who bring up fat children because it is a form of abuse which probably condemns them to a shorter and less healthy life' (Portillo, Sunday Times, $28^{\text {th }}$ October, 2007, p.17).

In the somewhat desperate search for 'solutions' to the reported health problems resulting from obesity and sedentary living, commentators, academics and policy makers have identified schools and physical education (PE) teachers as possible candidates (see for example Trost, 2006). Indeed, McKenzie and Lounsbery (2009) famously described school PE as 'the pill not taken'. It is certainly true that many countries in the world have a trained, professional PE workforce that has claimed, historically, to encourage children to be physically active for life. Moreover, governments expect PE to at least contribute to this aspiration through the provision of compulsory curriculum time each week throughout much of a young person's school career. It is worth emphasising the point, therefore, that there is little robust historical or contemporary evidence to suggest that PE in most countries has achieved anything significant in terms of encouraging lifelong engagement in physical activity or improving public health (Trost, 2006).

The purpose of this paper is to contribute to ongoing discussion in the international physical education community about the role of PE in public health (see for example, Haerens, Kirk, Cardon \& De Bourdeaudhuij, 2011 and Puhse, Barker, Brettschneider, Feldmeth, Gerlach, McCuaig, McKenzie \& Gerber, 2011). In particular, we suggest that although there has been much written about 'PE-for-health' curriculum activities and interventions, there has been rather less attention paid to the development of 'PE-for-health' pedagogies that might enable the PE profession to make a more robust contribution to public policy and practice in this field. We need to clarify at the outset that we are not arguing that health should be the only or even the main focus of PE. Indeed, we would support many of the arguments made by authors such as Evans, Rich \& Davies (2004), Gard (2004) and most recently Wellard (2012) who caution against focussing PE on narrow definitions of health and, in particular, obesity reduction. Instead, our discussion considers how PE might be more successful in achieving one of its key stated aspirations - encouraging lifelong engagement in physical activity. 
The paper is organised into five sections: (i) a summary of the claims made for the role of PE in delivering improved health outcomes; (ii) an overview of PE in different historical moments and analysis of the health pedagogies associated with each period; (iii) a summary of the evidence about the effectiveness of PE practices in the broad field of physical activity/health promotion; (iv) an assessment of the training needs and status of physical education teachers in this field; and (v) suggestions to inform the development of new 'PE-for-health' pedagogies to underpin an enhanced - yet realistic role for physical education in public health. In short, our purpose in this paper is to stimulate discussion on the potential of working across traditional discipline boundaries to develop new, complex, 'PE-for-health' pedagogies. The illustrative case study for this paper is health within physical education in England, although this specific case is grounded in the wider international literature.

\section{Claims Made for the Role of PE in Delivering Public Health Outcomes}

It is worth beginning this discussion by restating the obvious point that virtually all children and young people attend school - so the potential is there, from a public health education perspective, to reach them. Furthermore, there is an assumption built into most national and international policy documents on physical education (and school sport) that PE has a role in promoting, if not delivering, health benefits. For example, the International Council for Physical Education and Sport Science (ICSSPE, 2001) claimed that PE helps children to develop respect for the body and also develops an understanding of the role of aerobic and anaerobic physical activity in health. Similarly, in England, the national curriculum states that physical education should ensure that pupils develop competence and confidence to take part in a range of physical activities that become a central part of their lives, both in and out of school (Qualifications and Curriculum Authority, 2007).

It has been widely argued that there is a close relationship between PE and health; indeed, Green (2002a, p. 95) refers to PE's 'taken for granted role in health promotion'. Shephard and Trudeau (2000) argued that the most important goal of PE is the long-term health of students through their exposure to a wide range of health-giving forms of physical activity. Similarly, McKenzie (2007a) has long argued that PE is a suitable 
vehicle for the promotion of active, healthy lifestyles among young people, and Trost (2006) considers PE to be 'uniquely situated' to address the epidemic of obesity and sedentary behaviour. In addition, as was noted in the earlier example from the English national curriculum, there is an enduring belief that PE can affect leisure-time engagement in physical activity through positive activity experiences and exercise education (Vilhjalmsson \& Thorlindsson, 1998). Given these views, it is not surprising that the adoption and maintenance of physically active lifestyles is one of the established curricular goals of PE in many countries (see, for example, the Australian Curriculum and Reporting Authority [ACARA], 2011; and the National Association for Sport and Physical Education [NASPE], 2004).

At the same time, as has also been noted, it is important to be realistic about what is possible given that $\mathrm{PE}$ represents less than $2 \%$ of a young person's waking time. By itself, PE is unable to deliver young people's total physical activity needs (Fox \& Harris, 2003; McKenzie \& Lounsbery, 2009) although it does aim to deliver a strong education about the benefits of lifelong engagement in physical activity. In addition, it is important to remember that many countries around the world have witnessed a decrease in PE curriculum time in recent years (WHO, 2003). Exceptionally, PE time in England increased as a result of enthusiastic government funding (Office for Standards in Education [Ofsted], 2005). Even in the English context, however, a recent change of government has led to new policies that may result in a reduction in curriculum time for PE (Gove, 2010). It is also worth noting that the widely reported evidence about low levels of adult physical activity engagement would suggest that PE has been largely ineffective in converting education and understanding about physical activity for health into lifelong engagement.

In a wide ranging profile of the current and historical links between PE and physical activity, McKenzie and Lounsbery (2009) conclude by endorsing the American Heart Association's (AHA) position on the key role of schools in the provision of physical activity for youth. These authors emphasise a need to ensure the school environment is conducive to physical activity, and they highlight the importance of four specific AHA recommendations: (i) schools should deliver evidence-based health related PE; (ii) PE should be taught by qualified PE teachers; (iii) schools should be held 
accountable for the PE programmes they offer in schools; and (iv) 'Colleges and universities should provide professional preparation programs that produce teachers who are highly qualified to deliver evidence based physical education and health education programs' (p. 224, our emphasis).

In this paper, we would like to probe further the fourth recommendation cited above. In particular, we found the historical analysis that informed McKenzie and Lounsbery's (2009) paper to be helpful. Taking PE mainly in the USA as their case study, the authors were able to highlight a number of ways in which the low status of PE in schools has been a key factor in limiting the impact of PE in delivering effective health-related programmes. What seems to be missing from their discussion, however, is a focus on the pedagogies that teachers might use - or have used in the past - to enable them to effectively educate diverse children and young people about physical activity for their health (rather than deliver programmes to them). Indeed, we would identify knowledge about complex and effective 'PE-for-health' pedagogies as a significant gap in the existing literature in this field.

In this paper, therefore, we follow the lead taken by McKenzie and Lounsbery (2009) by undertaking an historical perspective on health within PE, although our case study is England. In particular, we consider the ways in which policies and practices prevailing at different moments in the history of PE in England are suggestive of specific health-related pedagogies. For the purposes of this paper, we adapt Armour's (2011) holistic definition of sport pedagogy to inform the notion of a 'PE-for-health' pedagogy. Armour's definition builds on the work of Kirk, Macdonald, and O'Sullivan (2006), Rovegno (2003), Grossman (1989), and Shulman (1987, p.13) to define pedagogy as an interdisciplinary concept with 'three complex dimensions that are made even more complex as they interact to form each pedagogical encounter'. The three dimensions are: knowledge in context, learners and learning, and teachers/teaching. Based on this understanding of pedagogy, 'PE-for-health' pedagogies would be inclusive of programmes/activities and teaching/coaching approaches, but would place the needs of the individual young learner in each pedagogical encounter at their core. We will explore this concept further in section (v) of this paper.

\section{Historical Overview of the Links between Health and Physical Education}


In this section, key moments in the history of health within PE in England are summarised. This necessarily brief overview highlights the sheer weight of claims made about a link between PE and health, and the strength of expectations - largely unmet that PE should be an effective public health tool. More interestingly, perhaps, this overview also points to the ways in which the claims made about health - or the links to health in PE - are suggestive of particular health pedagogies (or what we have termed 'PE-for-health' pedagogies).

\section{0-1950s: Pedagogies of Systematic Exercise for Health}

The Education bill of 1870 provided the first opportunity for every child in England to receive schooling, and it was noted that the physical fitness/condition of children was a major concern to be addressed. 'Drill' was, therefore, introduced into schools and this marked the first official recognition that children should take exercise as part of schooling. Drill was a severe form of exercise, but it was in line with the prevailing pedagogy that centred on instilling habits of obedience, smartness, order and cleanliness (see Roth, 1879). The policy was enacted in schools and, for example, in one local authority, the School Board recommended that 20 minutes each day should be devoted to physical exercises for all pupils (Birmingham School Board, 1886).

Between 1904 and 1914, physical education was explicitly linked to the physical welfare services, which included the provision of school meals and medical inspections. There are echoes here of the findings of McKenzie and Lounsbery (2009, p. 222) who argue that in the USA, 'The founding fathers of physical education were medical doctors'. For example, a key government document in the UK noted that: 'the primary objective of any course of physical exercises in schools is to maintain and, if possible, improve the health and physique of the children' (Board of Education, 1909, p. 9). Thus, although 1922 saw rising unemployment and pressing social problems outside school, the cost of delivering physical activity in schools was justified as a form of preventative medicine through the use of therapeutic exercise (for example, related to posture).

The 1933 syllabus of physical training (Board of Education, 1933, p. 6) marked an important development in physical education in England; it claimed that 'it is beyond question that without healthy conditions of the body, the development of mental and moral faculties is seriously retarded, and in some cases, precluded' (cited in Kirk, 1992) 
and references were made to early health movements (such as drill, Swedish gymnastics and therapeutic PE). Here again in this syllabus, there was a strong recommendation that a daily period of exercise was required in order to develop children's physiques. This was described in the syllabus as a matter of national importance. The syllabus also points to the importance of teachers and hints at pedagogical considerations: 'A practical syllabus and a competent teacher are the first essentials necessary for useful [physical] training' (Board of Education, 1933, p. 18); a point that will be picked up again in section (iv) of this paper.

One of the key points to note from this period, however, is that in England in 1933, the physical education and medical professions were closely aligned; including a PE committee of the British Medical Association. In 1936 this committee endorsed the notion that a daily exercise period was necessary for all children in school. As was noted earlier, a strong link between the medical and teaching professions was also evident during this period in the USA, although Lawson (1992) was critical of the ways in which the 'cultural authority' of different professionals concerned with health differed. Indeed, Lawson concluded that: 'The hegemony of medicine remains' (p.106) resulting in a prevailing view of health that is unhelpful to the aims of the physical education profession. The important point to be drawn from all of this is that PE was closely linked to medical notions of health, and there is evidence to suggest that pedagogical practices were similarly aligned. In this sense, structured physical exercises (drill) were considered to be sufficient to achieve the ends of improving health through physical education.

\section{0s-1980: Pedagogies of Movement Education}

A major ideological shift took place in England in the 1950s and 60s, away from drill and prescribed exercises to freer forms of developmental movement. This included the encouragement for teachers to develop new, complex pedagogies that were felt to be appropriate to meet the needs of growing children. Crucially, the requirement for daily exercise was lost and head teachers were allowed to determine how much time was devoted to PE based on an assessment of their pupils (see Planning the Programme, Ministry of Education, 1953). There was some concern expressed at the time about the ability of teachers to deliver PE in the new format (Edmunson, 1956). 
A major government report in 1967 (The Plowden Report) further endorsed the shift in focus in PE that had already begun, and supported the use of the term 'movement' rather than physical exercise, explaining: 'the aim is ...to develop each child's resources as fully as possible through exploratory stages and actions which will not be the same for any two children' (Central Advisory Council for Education, 1967, para 705). It could certainly be argued that in order to be successful, both pedagogies and practices would have needed to shift dramatically to meet the requirements of this new conceptualisation of children's physical activity needs.

\section{0 to 2000: Pedagogies of Science for Health}

The period from 1980 witnessed a resurgence in traditional health discourses within Physical Education, although it could be argued the focus was more holistic than in earlier years, encompassing aspects of psychological as well as physical health (Fox \& Biddle, 1988). In England, this led to a range of somewhat confusing and arguably limited approaches to health within physical education; for example health-related exercise and health-related fitness (Cale \& Harris, 2005). In Scotland and Australia during this period, a number of innovative (but unsustainable) daily health-related PE programmes emerged (Kirk, 1991; Pollatschek \& O’Hagan, 1989).

In the mid 1990s, international research reaffirmed the importance of regular physical activity across the lifespan (USDHHS, 1996) which led to age-appropriate national physical activity guidelines being established for children and youth (Health Education Authority, 1998; NASPE, 1995, 2002). The consequence of these developments was that the role of physical education in promoting lifetime physical activity became even more widely accepted (Green, 2002; Penney \& Jess, 2004) although the impact of the physical activity guidelines on school curricular programmes was minimal (Cale \& Harris, 2005). Moreover, the evidence base was somewhat limited with questions remaining about: claims that physical activity can deliver significant health benefits for young people (Biddle et al., 2004); the extent to which physical education can set the foundation for lifelong physical activity (Trudeau et al., 1999); and the tracking of physical activity from childhood through to adolescence (Trost, 2006).

A key feature of this period was recognition of the need to develop appropriate knowledge, understanding and behavioural skills (Fairclough \& Stratton, 2005) in the 
area of health. Evidence was beginning to suggest that educational and psychological approaches were more likely to achieve long-term engagement in physical activity than fitness programmes alone or a focus on the 'amounts' of physical activity accumulated in PE classes (see Bailey et al., 2009). Kirk (1986) recognised that traditional methods of learning were largely inappropriate as teachers needed to be able to deal with new concepts, information and skills which demanded different ways of structuring learning experiences. Alternative approaches were required which involved teachers in 'deskilling' and 'reskilling' (Colquhoun, 1989). Yet, despite a renewed and rhetorical interest in health within PE and some degree of experimentation during this period of time, none appeared to translate into major adjustments to the format of PE in schools or new pedagogical actions or, indeed, any radical changes to traditional practice.

\section{0-2010: Pedagogies of Weight Management and Obesity Reduction}

Despite equivocal evidence about the impact of physical education on engagement in lifelong physical activity, Green (2000) and Harris and Penney (2000) have noted that UK government policy, among others, has continued to emphasise the importance of physical education in providing opportunities for young people to become independently active for life (Department of Health [DoH], 1999; Department for Culture, Media and Sport, 2001). Moreover, in the UK, the government's focus from 2000 shifted to a broader conceptualisation of the 'healthy school' (see 'National Healthy School Status. A Guide for Schools', Department for Education and Skills \& DoH, 2005). In this initiative, 'physical activity' was identified as one of four compulsory core themes in a healthy school (alongside 'personal, social and health education', 'healthy eating' and 'emotional health and well-being'). Previous versions of the 'healthy school' initiative had included physical activity as an optional theme, but this resulted in few schools selecting it.

One of the last acts of the previous national government in the UK was the launch of an initiative entitled 'Healthy Weight, Healthy Lives: A Cross-Government Strategy for England' (DoH and Department for Children, Schools and Families [DCSF], 2008). The overall aim of the strategy was, by 2020: 'to reduce the proportion of overweight and obese children to 2000 levels' (ibid, page v). Key elements of the strategy included: 'developing tailored programmes in schools to increase the participation of obese and 
overweight pupils in PE and sporting activities' (ibid, page xii) and 'developing a fresh set of programmes ensuring there is a clear legacy of increased physical activity leading up to and after the 2012 Olympic Games' (ibid, page xiv). The key point here is that there was an underlying assumption that something new was needed in schools to meet children's individual physical activity/health needs. Yet, here again, there is little evidence to suggest that PE programmes or pedagogies changed significantly. Indeed, over the period of a decade, Harris (1997) and Leggett (2008) revealed that PE teachers' 'fitness for life' philosophies continued to be expressed mostly in the form of 'fitness for sport performance' practices. Much of this is, perhaps, unsurprising given that there was (and remains) a very limited focus on health in initial teacher education and continuing professional development (Ward, 2009).

\section{0-current: Pedagogies of Health through Competitive Sport}

Most recently in England, the new Coalition government has developed an initiative entitled 'Healthy Lives, Healthy People' (DoH, 2010a) and this, too, highlights the importance of schools and physical education in the promotion of physical activity for health. In addition, the Department for Education (DfE) has stated:

Children need access to high-quality physical education (PE), so we will ensure the requirement to provide PE in all maintained schools is retained and we will provide new support to encourage a much wider take up of competitive team sports (DfE, 2010, p.45).

It is apparent there is now a shift in focus towards engagement in competitive sport as the means to motivate children to be physically active and, more broadly, engage them in education and society. This is linked to the forthcoming Olympic Games in London 2012 and the promises made to deliver a sport participation legacy from them - particularly for those groups who currently have the lowest sport/physical activity participation levels (adolescent girls and some ethnic minority groups). It could be argued that this is a dramatic shift in ideology informing the ways in which children should be encouraged to become physically active through school PE. Moreover, if the government's aspirations are to be realised, it seems that new 'PE-for-health' pedagogies specifically linked to competitive sport will be required. This is a matter of some concern given the weight of 
evidence suggesting that physically inactive and low participation groups tend to find traditional competitive sports unappealing (Green, 2002b; Smith and Parr, 2007).

In summary, key moments in the history of PE in England have illustrated the different ways in which aspirations for the delivery of health and physical activity outcomes have been expressed over time. As was noted earlier, England is neither alone nor unusual in its emphasis on the role of schools and PE in health promotion. The U.S. Department of Health and Human Services (USDHHS) $(1997,2000)$ has produced guidelines and public health objectives founded on school physical education's role in promoting health-enhancing physical activity in young people. Similarly, in Australia, the Ministerial Council on Education, Employment, Training and Youth Affairs (MCEETYA) has emphasised that schools should develop pupils who 'have the knowledge, skills, understanding and values to establish and maintain healthy, satisfying lives' (MCEETYA, 2008, p.9). If anything, expectations that PE will contribute to wider public health outcomes through the promotion of active lifestyles appear to be intensifying. Yet, in looking back over the historical review, two points are clear. Firstly, health expectations linked to PE have changed through history, reflecting political and ideological shifts in understandings about the health needs of children. Yet, apart from the changes in pedagogy from 'drill' to 'movement' between the 1930s and the 1950s and some experimentation during the 1980s and 1990s, there is little evidence that any dramatic shifts in pedagogy have taken place. This conservatism might also explain some of the evidence in the next section about the reported ineffectiveness of PE in delivering improved health outcomes for children.

\section{Evidence for the Effectiveness of PE in Public Health}

Trost (2006) conducted a widely cited review of the evidence base supporting claims made about the health benefits of physical activity in childhood and its links to adult health. Although he later supported the 'unique role' of PE in addressing obesity and sedentary behaviours, Trost (2006, pp. 163-4) highlighted evidence showing that: '...there is currently little evidence to suggest that childhood physical activity has a significant influence on health outcomes during adulthood'. Nonetheless, aspirations for the role of physical education in promoting lifelong physical activity persist. In the USA, USDHHS (1997, 2000) guidelines recommended daily PE, specialist PE staff, and 
increased physical activity in lessons supported by appropriate curricula, and set public health objectives requiring more daily PE and increased activity levels within each class. In England, both the annual report of the Chief Medical Officer (DoH, 2010b) and the government's revised physical activity guidelines issued for all age groups ( $\mathrm{DoH}, 2011)$ have highlighted schools (and school PE) as instrumental in promoting and facilitating physical activity amongst young people.

Despite governmental aspirations for PE, questions remain about the quality and focus of PE programmes in the area of health, and about the abilities of PE teachers in this regard. What appears to be missing from the debate is any clear understanding of the pedagogies that are most likely to lead to the desired outcomes of increasing physical activity engagement and sustaining that increase during and beyond school years. Thus, although Trost (2006) points out that teacher training will need to 'bring a legitimate public health perspective' and that physical education teachers will need to 'become critical consumers of scientific information pertaining to youth physical activity and public health' (p. 184), there is little guidance on how this might be linked with specific pedagogies in practice.

It is important to note that reviews of existing health-related PE programmes have shown some potential for positive outcomes. Such outcomes include increased health knowledge, activity and fitness levels and improved attitudes towards physical activity (Almond \& Harris, 1998; Fox \& Harris, 2003; Harris \& Cale, 1997; Stone et al., 1998). However, few of these programmes are easily replicated because they require extensive curricular time and high levels of funding. In addition, the numerous health-related PE and physical activity initiatives and developments introduced in England over recent decades (see Cale \& Harris, 2005) have rarely been evaluated rigorously, meaning that little has been learnt from them (Fox \& Harris, 2003). The evidence base for the success of physical education in improving public health is, therefore, somewhat limited. In addition, there are enduring concerns about PE teachers and whether they have the knowledge and skills to educate pupils about physical activity in effective ways.

\section{PE Teachers and their Training in the Field of Health}

Aspirations, policies and ideologies regarding the role of PE in delivering public health outcomes may be laudable; but if PE teachers lack the content knowledge and 
pedagogies to deliver elements of health education effectively, it seems unlikely that health aspirations will be realised. This issue becomes even more problematic when PE teachers themselves fail to recognise their own shortcomings. Studies by Cardon and De Bourdeaudhuij (2002) and Cale (2000) highlighted numerous gaps in PE teachers' knowledge and revealed that many PE teachers were unaware of such gaps. Indeed, it could be argued that much of the international PE community is uncertain about the precise nature of appropriate health knowledge to be covered in PE, the 'proper' role for PE in health and, perhaps most importantly, about the level of responsibility the profession should accept for children's (let alone adults') health outcomes. In order to illustrate these points, the findings of three studies are summarised.

\section{PE Teachers' Health Knowledge: An Example from England}

As part of the physical education teacher education (PETE) programme in her institution, one of the authors (author b, in press) recorded influences upon the development of PETE students' 'PE-for-health' knowledge, perceptions and experiences during their one year programme. Questionnaire data from 124 PETE students showed that at the outset of their programme, knowledge of appropriate/recommended physical activity levels for children was both limited and confused. Moreover, once the students entered schools to undertake practicum, their learning about health was severely limited by the entrenched practices encountered. For example, most students reported a prevalence of physiology-based teaching about healthy, active lifestyles, organised into discrete units of study and taught in isolation from the rest of the PE programme. It is unclear how such learning would transfer beyond the unit of study. In addition, the students were unable to comment on health pedagogies because the focus of the practice in schools was mainly on health content knowledge. Author $b$ concluded that the practices encountered by PETE students were unlikely to develop the kinds of dynamic 'PE-for-health' pedagogies that might promote healthy, active lifestyles.

\section{PE Teachers' Health Knowledge: An Example from the USA}

In a study on PE teachers' content knowledge in health related fitness (HRF), Castelli and Williams (2007) asked 73 middle school teachers to take a three part cognitive HRF test and self-efficacy questionnaire. The test was at the level expected of $9^{\text {th }}$ grade students (age 13-14 years). The findings were interesting in that although the 
teachers predicted they would do very well on the test, with $86 \%$ believing they would pass, only $38 \%$ of teachers passed at the level of performance required of a $9^{\text {th }}$ grade student. The authors described this as 'perplexing', suggesting one explanation that teachers' professional development in the field of health is simply inadequate. These authors also reported that: 'few physical education teachers participate in professional activities...that would provide current information regarding HRF' (Castelli \& Williams, 2007, p. 15). The findings of this study are similar to those of Harris (2005) who analysed PE teachers' uptake of health-focussed professional development modules in a recent national professional development programme in England. Harris found that there was a low uptake of the modules on health with most teachers opting for activity-specific modules such as games, dance and gymnastics. Taken together, it could be argued that these studies hint both at a level of PE teacher complacency in the field of health, and about the daunting complexity of the pedagogies required to change behaviour.

\section{The 'Source' of PE teachers' Existing Health Knowledge}

A nationally representative survey of secondary school (11-16 years) PE teachers in England ( $\mathrm{n}=112)$ was undertaken to find out about the sources of the health knowledge upon which they were basing their practices (Ward, 2009). For half of the teachers in this study, HRE had not been covered as part of their PETE programmes. Furthermore, over three-quarters of the teachers reported that they had not engaged in any health-focussed continuing professional development in the previous 12 months; with over two thirds reporting none in the previous three years. This suggests that in England at least, PE teachers are basing their health-related practices on limited (or no) specific 'official' and current health knowledge. Here again, these findings cast doubt on the ability of PE teachers to deliver significant health outcomes through their programmes.

These three illustrative studies suggest that PE teachers may lack both the requisite health knowledge and appropriate 'PE-for-health' pedagogies. Furthermore, although there has been some attention paid to the former - identifying appropriate health content knowledge - there has been surprisingly little new knowledge on health pedagogies that could support PE teachers in re-contextualising (Bernstein, 1990) health knowledge to meet the diverse needs of their pupils. In this paper, therefore, we would like to argue for a renewed focus in the PE profession (and beyond) on developing what 
we have termed 'PE-for-health' pedagogies. We present some ideas on the foundations upon which 'PE-for-health' pedagogies could be developed and identify three practical steps towards their development.

\section{Towards the Development of New 'PE-for-Health' Pedagogies}

Earlier in this paper, we drew upon Armour's (2011) definition of sport pedagogy to introduce the notion of 'PE-for-health' pedagogies. We argue that these pedagogies should have, at their core, the pedagogical encounter; i.e. the precise moment where a professional teacher (or coach) is engaged in meeting the diverse learning needs of an individual young learner in PE or sport. From this perspective, the ability to diagnose the learning needs of young learners is paramount, and it is this diagnostic process that should drive the entire pedagogical process (Armour, Makopoulou \& Chambers, 2012). Implicit is a complete reversal of the prevailing pedagogical approach where curriculum/programme/activities are identified first and it is those - rather than the needs of individual young learners - that drive the educational process (including teacher education). We would argue that the prevailing approach has failed many young learners and is a key contributory factor in the reported low levels of physical activity engagement in the adult population.

Essentially, as has been widely reported elsewhere, entrenched health-related behaviours are usually far too complex to be changed by taking a simple exercise 'prescription' approach (Pringle \& Pringle, 2012; Mutrie \& Woods, 2003; Sallis \& Owen, 1999; Soos, Liukkonen, \& Thomson, 2007). What is needed in PE, therefore, is a more effective education strategy and a key part of such a strategy is the development of what we have termed, new 'PE-for-health' pedagogies. Such pedagogies take the young learner as their starting point, and are complex, three dimensional (as defined earlier), personalised, flexible and best-knowledge/evidence-based. Thus, in considering each of the three dimensions of the pedagogical process (the young learner, the curriculum, and the abilities of the teacher), it is the needs of clients - individual young learners - that must be privileged. In so doing, PE teachers can claim to be offering a truly professional educational service. Given that teaching is recognised as a profession, this would appear to be a reasonable expectation. 
There are problems in each dimension of existing pedagogies in the context of health within PE. Indeed, as was illustrated earlier, there is strong evidence to suggest that the enthusiasm of the profession's claims for the role of PE in health is not matched by the kinds of knowledge, skills and training that would support teachers to be effective. Two recent contributions to the academic literature are illustrative.

Puhse et al. (2011) identified shared concerns in the international community about the ways in which health-based PE programs are disseminated and taught in schools. Many of these concerns centre on teachers. For example, in a study in the US, McKenzie (2007b) complained that physical educators are rarely trained to be effective in teaching behavioural skills, promoting physical activity beyond the gymnasium, or doing the kind of social marketing required to encourage sustained physical activity engagement. Furthermore, a study by Lounsbery, McKenzie, Trost \& Smith (2011) argued that a lack of critical awareness and accountability in schools presented persistent barriers to the dissemination and adoption of evidence-based health-PE programmes. In Germany, it was reported that few PE programmes focus on health in any systematic or specialised way and that PE teachers tend to focus on developing young people's sporting abilities. In Australia, the recent Health and PE Key Learning Area (HPE KLA) is reported as 'an example of a 'best practice' program of HPE that is supported by robust research but that has failed to gain traction within the everyday practices of Australian schools' (McCuaig, 2008, cited in Puhse et al, 2011, p.9). As Tinning (2002, cited in Puhse et al, 2011, p.9) points out, Australian PE teachers have tended to resist efforts to engage in health and PE curriculum initiatives, particularly those that take a socially critical perspective or require dramatic shifts in content knowledge. Puhse et al (2011) conclude by arguing that what is missing in the field is a general framework illustrating clearly the ways in which physical educators can influence students' health. They also argue that it is unlikely that a best-practice model of health-related PE that would be applicable worldwide can be found, and that different, localised approaches towards health-related PE are both legitimate and desirable.

In the second contribution, Haerens et al. (2011) focus on the PE curriculum within a proposed pedagogical model for health-based PE (HBPE). They argue that in the context of seeking to achieve health education outcomes, the appropriateness of the 
traditional multi-activity sports-based curriculum offered in many schools should be questioned. Moreover, they point out that currently, 'there is no pedagogical model for HBPE' (Haerens et al., 2011, p. 324) and they emphasise the need for teachers to be willing to develop new knowledge/skills to teach lifelong engagement in health related physical activity. This leads Haerens et al to propose 'valuing a physically active lifestyle' as the conceptual foundation for a new HBPE pedagogical model with a major focus on the affective domain. Moreover, these authors propose putting in place a systematic, developmental process for the new model including: the formulation of a consensus document on best practice/evidence in health; piloting; implementation of different versions of the model across a wide range of contexts; validation; further research on the impact of the model on teachers' philosophies and teaching styles; and the collection of robust data on the intended learning outcomes in and beyond school.

We support the case made by Puhse et al (2011) that a general framework for health within PE is missing, and that localised needs/agendas must be accommodated. We also support the suggestions made by Haerens et al (2011) about the development of a new pedagogical model for health-based PE and, in particular, we find the underpinning notion of 'valuing a physical activity lifestyle' to be compelling. We would like to argue, however, that their proposals have the potential to suffer weaknesses similar to those identified in the review of existing practice undertaken by Puhse et al (2011). In particular, as McQuaig (cited in Puhse et al, 2011) concluded, in the Australian context:

'Unfortunately, the failure to mobilise the pedagogical and philosophical richness of the most recent Australian HPE syllabus documents has ensured that what stands for best practice in Australian PE spends more time on teachers' bookshelves than in the vibrancy of their classrooms' (p. 10).

Herein rests the nub of the problem. No matter how rich, complex and evidence-based a new framework, policy, model, or resource is, it will fail to achieve what it promises if PE teachers are not persuaded to change their pedagogies and practices. This explains our argument that the development of new 'PE-for-health' pedagogies is the next step to be taken in identifying a credible role for PE in public health. Importantly, we have framed our arguments around a clear understanding of teaching as a profession that exists to serve its clients (Armour \& Makopoulou, 2012). By identifying these clients as children 
and young people who, by definition, have diverse learning needs, we seek to switch the focus for development from external pressure to internal professional responsibility to change pedagogies and practices. Moreover, in the case of health within PE, this shift in focus is pivotal because it ensures that instead of attempting to teach 'health' - rather crudely - as a global concept, it has to be taught at the refined level of the individual.

There is a wealth of historical and current research evidence to suggest that there is little point in trying to bypass teachers in a curriculum or pedagogical innovation. As Guskey, (2002) has shown us, if a new development is to be successful, it is essential that teachers 'buy in' to it. Guskey points out that this renders much traditional professional development ineffectual because it is designed to persuade teachers to change their philosophies before they are able to see evidence of the benefits in their practice. In addition, the traditional CPD model - 'one-shot', stand-alone, out of context, and without follow-up support - flouts almost everything we know about how adults learn (Tusting \& Barton, 2003). The point of all this in the context of this paper is that when physical educators venture into the field of health, where best knowledge changes rapidly and constantly (Pringle \& Pringle, 2012), the ways in which that knowledge is developed and made available to the teaching profession need careful consideration.

Teachers' responses to a state mandated curriculum change centred on public health in the USA were studied by Cothran, McCaughtry, Kulinna, \& Martin (2006). In summary, training for teachers was provided, but there was little follow-up support. Teachers felt overwhelmed by what was being offered, and unable to absorb all the information. Furthermore, teachers reported that the knowledge failed to relate to their personal worlds of teaching - so they rejected it:

I came home and as a couple of days passed I thought 'now wait a minute, how does this work and how does that work?' (p. 539)... In a way it's a kind of fantasy world when you go to those trainings because it's not the real world. ..I think sometimes they were kind of fantasy (p. 542).

In summary, therefore, we would argue that if the physical education profession is going to continue to make claims that one of its core aims is an aspect of health promotion through encouraging lifelong engagement in physical activity - there is an urgent need to help teachers to develop new, effective 'PE-for-health' pedagogies. To stimulate debate 
on the nature of such pedagogies in practice, we propose the following three steps as the essential starting point in making meaningful and sustainable changes to PE practice.

\section{Step One: Find New Ways to Collaborate with Appropriate Professional Health Expertise from Outside PE}

We argue that it could be fruitful to revive the historical links between the PE and medical/wider health professions. It is important, however, to learn the lessons from history (see earlier sections of this paper) and to ensure that each profession can contribute appropriate expertise. Whereas medical/health/exercise science professionals might be responsible for identifying - and updating - best health content knowledge upon which PE practices should be based, it is the PE profession that bears the responsibility to develop pedagogies to re-contextualise that knowledge to meet the learning needs of diverse children in schools. In other words, we would argue that the PE profession should focus on developing and contributing unique professional knowledge both on how broad categories of children engage (realistically) with physical activity/health messages, on how individual children can learn most effectively, and on appropriate curriculum content.

In order to develop the requisite professional knowledge, we would argue that PE teachers will need to undertake - routinely - much more detailed analyses of individual children's diverse learning needs than is currently the norm. In turn, this will require the kind of multi/inter/and trans-disciplinary knowledge of children and physical activity that is unlikely to be developed in a traditional version of PE. It seems clear to us that PE-forhealth pedagogies must go beyond teaching sports skills or delivering fitness curriculum content to children en masse. This latter point leads to Step 2.

\section{Step Two: Ensure that Health Pedagogies within PE are Centred on the Diverse and Dynamic Learning Needs of Young Learners}

In the burgeoning field of exercise science, it is becoming increasingly clear that individuals respond to exercise in different ways at different times for different reasons (see, for example, Bouchard, Rankinen \& Timmons, 2011; Bray, 2000). Exercise promotion/prescription, therefore, focuses on personalised, individualised and flexible approaches and a recognition that constant updating is required to adapt to individuals' changing circumstances (whether they be physiological, psychological, social or 
economic in nature) (Mutrie \& Woods, 2003). In physical education, on the other hand, we still tend to batch-process children and young people through common sport and physical programmes at a predetermined rate with predetermined outcomes. This seems to run counter to contemporary knowledge about the ways in which people will need to manage and constantly adapt their personal exercise programmes throughout the life course. In other words, traditional forms of PE could be regarded as limited preparation for a lifetime of physical activity.

In order to develop new PE-for-health pedagogies, therefore, we would argue that there are two considerable challenges facing the PE profession. Firstly, PE teachers need to be supported to develop knowledge and skills that will better prepare them to diagnose effectively the individual health/physical activity learning needs of children and young people. Secondly, the organisation of PE in schools needs to be structured differently to ensure that as pupils reach secondary school (age 11/12) they are increasingly empowered to develop and manage sport/physical activity/exercise programmes that work for them as individuals. The traditional PE lesson - rushed and sandwiched between two classroom-based lessons - may simply be inappropriate to prepare contemporary adolescents for lifetime engagement in physical activity. Furthermore, we would argue that PE should extend beyond the school setting to a much greater extent than it currently does, and should be working ever more closely with local sports coaches. Taking step two, however, signals fundamental changes to PE teacher education and career-long professional development... which leads to our suggested step three.

\section{Step Three: Re-conceptualise PE Teaching as a Continuous Process of (Career-long)}

\section{Professional Learning about Pupils and their Individual and Dynamic Learning}

\section{Needs}

As was noted earlier in this paper, there is now a wealth of knowledge available on adult learning generally, and teacher learning specifically. Although there is continuing debate about the most effective ways to structure teachers' CPD (Desimone, 2009) there is a clear recognition that traditional methods, on their own, do not meet teachers' needs. This is a concern in all areas, but in the area of health/physical activity education in PE, it could be argued that this issue is of particular concern. 
We would argue, building on Steps One and Two, that if the PE profession is serious about its role in promoting lifelong health and wellbeing, it has a professional responsibility to ensure that its practitioners are fit for purpose. Professional learning, therefore, at both pre- and post- qualification level, should be centred on the core focus of the PE profession: the individual child or young person as learner in physical activity. What is required is minute and detailed observation and analysis of individual learners that can be recorded, shared and built up as a resource across the profession over time, forming the core of professional learning in PE. Given that they are members of a profession, we would argue that PE teachers have a responsibility to children and young people to ensure that within the three dimensions of pedagogy identified earlier, the dimensions of teacher knowledge/expertise and curriculum knowledge are centred on the dimension that is at the heart of the profession: the needs of young learners. This is not merely a matter of semantics. Taken to its logical conclusion, the shift in emphasis suggested here would revolutionise practice. Some might argue that at a practical level, it is impossible for PE teachers to treat children as individual learners. Yet, this is precisely what the teaching profession claims to do and, as Tinning $(2012,124)$ argues, accepting the pressures to link PE and health ever more closely might result in significant changes to our 'idea of the idea of physical education'.

\section{Conclusion}

In this paper we have argued that the development of new 'PE-for-health' pedagogies is the next major step to be taken in finding a valuable - and valued - role for PE in the wider context of health. We have drawn on highlights from the history of PE in England to illustrate that while health has been expressed differently in PE over time, there is little evidence that pedagogies have changed. We have defined 'PE-for-health' pedagogies as complex, three dimensional, personalised, flexible and bestknowledge/evidence-based. In particular, we have suggested that such pedagogies have client learning needs at their core, with children and young people identified as the core clients. In emphasising that PE is a profession, we have focussed on the professional responsibility of teachers to meet the diverse learning needs of their clients in the area of health. This has led us to suggest three practical steps towards the development of new 'PE-for-health' pedagogies that are centred on the pedagogical encounter. We would 
argue that it is impossible to prescribe the precise nature of PE-for-health pedagogies before taking the three steps identified in this paper. There is no quick fix for the situation in which the PE profession finds itself with regards to health, and we look forward to further debate on this topic. 


\section{References}

Aaronovitch. D. (2007). The obesity debate: clarity begins at home. The Times, 16th October, 2007, p.17.

Almond, L., \& Harris, J. (1998). Interventions to promote health-related physical education, In S. Biddle, J. Sallis \& N. Cavill (Eds.), Young and active? Young people and health-enhancing physical activity - evidence and implications (pp.133-149). London: Health Education Authority.

Armour, K. (2011). What is ‘sport pedagogy' and why study it? In K. Armour (Ed.) Sport pedagogy. An introduction for teaching and coaching (pp.11-23). London: Pearson.

Armour, K.M. \& Makopoulou, K. (2012). Great expectations: Teacher learning in a national professional development programme. Teaching and Teacher Education, I-First: http://dx.doi.org/10.1016/j.tate.2011.10.006.

Armour, K.M., Makopoulou, K. \& Chambers, F.C. (2012). Progression in PE teachers' career-long professional learning: Conceptual and practical concerns. European Physical Education Review, 18(1), 62-77; doi: 10.1177/1356336X11430651

Australian Curriculum and Reporting Authority (ACARA) (2011). Australian curriculum. Retrieved December, 28, 2011 from http://www.acara.edu.au/curriculum/curriculum.html

Australian Institute of Health and Welfare (AIHW) (2010). Australia's health 2010. Australia's health series no. 12. Cat. No. AUS 122. Canberra: AIHW.

Bailey, R., Armour, K., Kirk, D., Jess, M., Pickup, I., Sandford, R., \& the BERA Physical Education and Sport Pedagogy Special Interest Group (2009). The educational benefits claimed for physical education and school sport: An academic review. Research Papers in Education, 24(1), 1-27.

Bernstein, B. (1990). The structuring of pedagogic discourse. London: Routledge.

Biddle, S.J.H., Gorely, T., \& Stensel, D. (2004). Health-enhancing physical activity and sedentary behaviour in children and adolescents. Journal of Sports Sciences, 22, 679-701.

Birmingham School Board (1886). Birmingham School Board Report. Reference Library Birmingham, UK. 
Board of Education (1909). Syllabus of physical exercises. London: HMSO.

Board of Education (1933). Syllabus of physical training for schools. London: HMSO.

Bouchard, C., Rankinen, T. and Timmons, J.A. (2011). Genomics, genetics and geneexercise interactions in health and disease. The American Handbook of Physiology. Comprehensive Physiology.

Bray, M.S. (2000). Genomics, genes, and environmental interaction: The role of exercise. Journal of Applied Physiology, 88(2), 788-792.

Cale, L. (2000). Physical activity promotion in schools - PE teachers' views. European Journal of Physical Education, 5(2), 158-167.

Cale, L., \& Harris, J. (Eds.) (2005). Exercise and young people. Issues, implications and initiatives. Basingstoke, Hampshire: Palgrave Macmillan.

Cardon, G., \& De Bourdeaudhuij, I. (2002). PE and physical activity in elementary schools in Flanders. European Journal of Physical Education,7(1),5-18

Castelli, D., \& Williams, L. (2007). Health-related fitness and physical education teachers' content knowledge. Journal of Teaching in Physical Education, 26, 319.

Central Advisory Council for Education (England) (1967). The Plowden report. Children and their primary schools. London: HMSO.

Colquhoun, D. (1989). Health related fitness and individualism: Continuing the debate. British Journal of Physical Education, 20(3), 118-122.

Cothran, D. J., McCaughtry, N., Kulinna, P. H., \& Martin, J. (2006). Top-down public health curricular change: the experience of physical education teachers in the United States. Professional Development in Education, 32(4), 533-547.

Department for Culture, Media and Sport (DCMS). (2001). A sporting future for all. The Government's plan for sport. London: HMSO.

Department for Education (2010). The importance of teaching. The schools white paper 2010. London: HMSO.

Department for Education and Skills (DfES) \& Department of Health (DoH) (2005). National healthy school status. A guide for schools. London: DfES \& DoH. Department of Health (DoH). (1999) Our healthier nation. London: HMSO. Department of Health (DoH) (2010a). Healthy lives, healthy people. Our strategy for 
public health in England. London: HMSO.

Department of Health (DoH) (2010b). Annual report of the Chief Medical Officer 2010. London: HMSO.

Department of Health (DoH) (2011). Physical activity guidelines for all ages. London: HMSO.

Department of Health (DoH) \& Department for Children, Families and Schools (DCSF) (2008). Healthy weight, healthy lives: A cross-government strategy for England. London: DoH.

Desimone. L.M. (2009). Improving impact studies of teachers' professional development: Toward better conceptualisations and measures. Educational Researcher, 38(3), 181-199.

Edmundson, J. (1956). Physical education teachers' handbook for primary schools. London: Evans.

Evans, J., Rich, E., \& Davies, B. (2004). The emperor's new clothes: fat, thin and overweight. The social fabrication of risk and ill-health. Journal of Teaching in Physical Education, 23, 372-391.

Fairclough, S., \& Stratton, G. (2005). Physical education makes you fit and healthy: Physical education's contribution to young people's activity levels. Health Education Research, 20(1), 14-23.

Fairclough, S., Stratton, G., \& Baldwin, G. (2002). The contribution of secondary school physical education to lifetime physical activity. European Physical Education Review, 8(1), 69-84.

Fox, K., \& Biddle, S. (1988). The child's perspective in physical education part 2: Children's participation motives. British Journal of Physical Education 19(2), 1782.

Fox, K., \& Harris, J. (2003). Promoting physical activity through schools. In J. McKenna \& C. Riddoch (Eds.), Perspectives on health and exercise (pp.181-201). Basingstoke: Palgrave Macmillan.

Gard, M. (2004). An elephant in the room and a bridge too far, or physical education and 
the 'obesity epidemic'. In J. Evans, B. Davies, \& J. Wright (Eds.), Body knowledge and control: Studies in the sociology of physical education and health (pp.545-549). London: Routledge.

Gove, M. (20th October 2010). Letter from Michael Gove MP to Baroness Sue Campbell. Physical education and school sport. London: Department for Education.

Green, K. (2000). Extra-curricular physical education in England and Wales: A sociological perspective on a sporting bias. European Journal of Physical Education, 5(2), 179-207.

Green, K. (2002a). Physical Education and the 'couch potato society' - part one. European Journal of Physical Education, 7(2), 95-107.

Green, K. (2002b). Lifelong participation, physical education and the work of Ken Roberts. Sport, Education and Society, 7(2), 167-182.

Grossman, P. L. (1989). A study in contrast: Sources of pedagogical content knowledge for secondary English. Journal of Teacher Education, 40, 24-31.

Guskey, T. R. (2002) Professional development and teacher change. Teachers and Teaching: Theory and Practice, 8 (3/4), 381-391.

Haerens, L., Kirk, D., Cardon, G., \& De Bourdeaudhuij, I. (2011). Toward the development of a pedagogical model for health-based physical education. Quest, $63,321-338$.

Harris, J. (1997). Physical Education: A Picture of Health? The Implementation of Health Related Exercise in the National Curriculum in Secondary Schools in England. (Unpublished doctoral thesis). Loughborough University, England.

Harris, J. (2005). Health-related exercise and physical education. In K. Green \& K. Hardman, Physical education. Essential issues (pp. 78-97). London: Sage Publications.

Harris, J., \& Cale, L. (1997). How healthy is school PE? A review of the effectiveness of health-related physical education programmes in schools. Health Education Journal, 56, 84-104.

Harris, J. \& Penney, D. (2000). Gender issues in health-related exercise. European Physical Education Review, 6(3), 249-273. 
Health Education Authority (1998). Young and active? Policy framework for young people and health-enhancing physical activity. London: Health Education Authority.

International Council for Physical Education and Sport Science (ICSSPE) (2001). World summit on physical education. Berlin: International Council for Physical Education and Sport Science.

Kirk, D. (1986). Health related fitness as an innovation in the physical education curriculum. In J. Evans (Ed.), Physical education, sport and schooling. Studies in the sociology of physical education (pp. 167-181). East Sussex: The Falmer Press.

Kirk, D. (1991). Daily physical education research: A review and critique. Daily physical education: Collected papers on health based physical education in Australia. Geelong: Deakin University Press.

Kirk, D. (1992). Defining physical education. The social construction of a school subject in postwar Britain. London: The Falmer Press.

Kirk, D., Macdonald, D., \& O’Sullivan, M. (2006) (Eds). The handbook of physical education. London: Sage.

Lawson, H. (1992). Toward a socioecological conception of health. Quest, 44(1), 105121.

Leggett, G. (2008). A changing picture of health: Health-related exercise policy and practice in physical education curricula in secondary schools in England and Wales. (Unpublished doctoral thesis). Loughborough University, England.

Lounsbery, M. A. F., McKenzie, T. L., Trost. S. G., \& Smith, N. J. (2011). Facilitators and barriers to adopting evidence-based physical education in elementary schools. Journal of Physical Activity and Health, 8, 17-25.

McCuaig, L. (2008). Teaching the art of health living: A genealogical study of HPE and the moral governance of apprentice citizens. (Unpublished doctoral thesis). University of Queensland, Brisbane, Australia.

McKenzie, T. (2007a, October). A public health perspective: For PETE's sake! Paper presented at the Historic Traditions and Future Directions in Research on Teaching and Teacher Education in Physical Education Conference, Pittsburgh, USA. 
McKenzie, T. L. (2007b). The preparation of physical educators: A public health perspective. Quest, 59, 346-357.

McKenzie, T.L., \& Lounsbery, M. A. F. (2009). School physical education: The pill not taken. American Journal of Lifestyle Medicine, 3(3), 219-225.

Ministerial Council on Education, Employment, Training and Youth Affairs (MEETYA) (2008). The Melbourne declaration on educational goals for young Australians. Canberra: Commonwealth of Australia.

Ministry of Education (1953). Planning the programme. London: HMSO.

Mutrie, N. \& Woods, C. (2003). How can we get people to become more active? A problem waiting to be solved. In J. McKenna \& C. Riddoch (Eds.), Perspectives on health and exercise (pp. 131-152). Basingstoke, Hampshire: Palgrave Macmillan.

National Association for Sport and Physical Education (NASPE) (1995). Moving into the future: National physical education standards: A guide to content and assessment. St Louis: Mosby.

National Association for Sport and Physical Education (NASPE) (2002). Active start. A statement of physical activity guidelines for children, birth to five years. Reston, VA: American Alliance for Health, Physical Education, Recreation and Dance.

National Association for Sport and Physical Education (NASPE) (2004). Moving into the future: National standards for physical education (2nd ed.). Boston: McGraw Hill.

Office for Standards in Education (OFSTED) (2002). Secondary subject reports 2000/01: Physical education. HMI 381. London: HMSO.

Office for Standards in Education (OFSTED) (2005). Physical education in secondary schools. London: HMSO.

Office for Standards in Education (OFSTED) (2009). Physical education in schools 2005/08. Working towards 2012 and beyond. London: HMSO.

Penney, D., \& Jess, M. (2004). Physical education and physically active lives: A lifelong approach to curriculum development. Sport, Education and Society, 9(2): 269287.

Pollatschek, J. L., \& O’Hagan, F. J. (1989). An investigation of the psycho-physical 
influences of a quality daily physical education programme. Health Education Research 4(3), 341-350.

Portillo, M. (2007). Personal responsibility. The Sunday Times, 28th October, 2007, p.17.

Pringle, R., \&Pringle, D. (2012). Competing obesity discourses and critical challenges for health and physical educators. Sport Education and Society, 17, 2, 143-162.

Puhse, U., Barker, D., Brettschneider, W. D., Feldmeth, A. K., Gerlach, E., McCuaig, L., Mckenzie, T. L., \& Gerber, M. (2011). International approaches to health-oriented physical education - local health debates and differing conceptions of health. International Journal of Physical Education, 3, 2-15.

Qualifications and Curriculum Authority (QCA) (2007). The national curriculum for physical education. London: QCA.

Roth, M. (1879). On the neglect of physical education and hygiene by parliament and the educational department, as the principal cause of the degeneration of the physique of the population. ISBN 10: 1437038255/ISBN 13: 9781437038255.

Rovegno, I. (2003). Teachers' knowledge construction. In: S. Silverman \& C. Ennis (Eds.), Student learning in physical education: Applying research to enhance instruction (pp. 295-310). Champaign, IL: Human Kinetics.

Sallis, J. F., \& Owen, N. Physical activity and behavioural medicine. London: Sage Publications.

Shephard, R. J., \& Trudeau, F. (2000). The legacy of physical education: Influences on adult lifestyle. Pediatric Exercise Science, 12, 34-50.

Shulman, L. (1987). Knowledge and teaching: foundation of a new reform. Harvard Review, 57, 1-22.

Smith, A., \& Parr, M. (2007). Young people's views on the nature and purposes of physical education: a sociological analysis. Sport, Education and Society, 12(1), $37-58$.

Soos, I., Liukkonen, J., \& Thomson, R. W. (2007). Health promotion and healthy lifestyles: motivating individuals to become physically active. In J. Merchant, B. L. Griffin, \& A. Charnock (Eds.), Sport and physical activity. The role of health promotion (pp. 103-117). Basingstoke, Hampshire: Palgrave Macmillan.

Stone, E.J., McKenzie, T.L., Welk, G.J., \& Booth, M.L. (1998). Effects of physical 
activity interventions in youth: Review and synthesis. American Journal of Preventive Medicine, 15(4): 298-315.

Tinning, R. (2002). Identity, politics and the challenges of preparing H-PE teachers to teach a socially critical curriculum: A tentative beginning. Paper presented at AIESEP, La Coruna, Spain.

Tinning, R. (2012). The idea of physical education: a memetic perspective. Physical Education and Sport Pedagogy, 17, 2, 115-126.

Trost, S. (2006). Public health and physical education. In D. Kirk, M. O’Sullivan, \& D. MacDonald (Eds.), Handbook of physical education (pp. 163-187). London: Sage.

Trudeau, F., Laurencelle, L., Tremblay, J., Rajic, M., \& Shephard, R. J. (1999). Daily primary school physical education: Effects on physical activity during adult life. Medicine and Science in Sports and Exercise, 31(1), 111-117.

US Department of Health and Human Services (USDHHS) (1996). Physical activity and health: A report of the Surgeon General. Atlanta: USDHHS.

US Department of Health and Human Services (USDHHS) (1997). Guidelines for school and community to promote lifelong physical activity among young people. Atlanta: USDHHS.

U.S. Department of Health and Human Services (USDHHS) (2000). Healthy people 2010: National health promotion and disease prevention objectives. Washington, DC: USDHHS.

US Department of Health and Human Services (USDHHS) (2008). Physical activity guidelines for Americans. Washington DC: USDHHS. Retrieved December, 28, 2011 from http://www.health.gov/PAGuidelines

Vilhjalmsson, R., \& Thorlindsson, T. (1998). Factors related to physical activity: A study of adolescents. Social Science and Medicine, 47, 665-675.

Wellard, I. (2012). Body-reflexive pleasures: Exploring bodily experiences within the context of sport and physical activity. Sport, Education and Society, 17(1), 21-33.

Ward, L. (2009). Physical education teachers' engagement with 'health-related exercise' and health-related continuing professional development: a healthy profile? (Unpublished doctoral thesis). Loughborough University, England.

World Health Organisation (WHO) (2003). Health and development through physical 
activity and sport. Geneva: WHO.

World Health Organisation (WHO) (2004). Global strategy on diet, physical activity and health. Geneva: WHO.

World Health Organisation (WHO) (2010). Global recommendations on physical activity for health. Geneva: WHO. 